\title{
Considering the legitimacy of homeless hostels as sites of discipline and regulation
}

\begin{tabular}{|r|l|}
\hline Journal: & International Journal of Sociology and Social Policy \\
\hline Manuscript ID & IJSSP-10-2018-0174.R1 \\
\hline Manuscript Type: & Original Article \\
\hline Keywords: & Homelessness, legitimacy, discipline, Regulation, social control \\
\hline \multicolumn{2}{|l}{} \\
\end{tabular}

SCHOLARONE $^{\text {m }}$

Manuscripts 


\section{Considering the legitimacy of}

\section{homeless hostels as sites
discipline and regulation}

\section{Homelessness and hostels in England and Wales}

"It's like prison. It reminds me of prison in a small way, it really does. Four white walls, you're in a room. You've got a curfew, you're told when to eat. You know, you have to do certain things. I don't know, it is a bit like big brother, and a bit like prison. I don't fuckin' like it to be honest. I'm not liking it at the moment." (Spanish, 25, Hostel 2)

Spanish had been living in a hostel for six weeks and drew attention to its disciplinary characteristics. Homeless hostels accommodate some of the most vulnerable and marginalized in society with the aim of helping them to become independent, autonomous citizens. However, their work is often underpinned by ideas surrounding homelessness as an individual failing, and fails to challenge the structural inequalities which form the backdrop to which homelessness remains a key societal issue. Even benign forms of support are often inseparable from coercive, regulatory, routinizing and surveillance strategies to which the homeless and other marginalized populations have historically been subjected.

There is little international agreement regarding what constitutes a hostel (Edgar and Meert, 2005). Cooper (2013) notes that the term covers, among others: homeless hostels, probation hostels, female refuges and drug rehabilitation hostels. There are now just over 35,000 bed spaces available for single homeless people in England; a reduction of 8,000 since 2010 (Crisis, 2018) due in a large part to a reduction in funding streams for the charities, councils and other organizations which operate them under the ongoing austerity regime in the UK. This is at a time when, mirroring increases in homelessness across all EU member states except Finland (The Foundation Abbé Pierre and FEANTSA, 2017). Rough sleeping more than doubled after 2010 to 4,751 on any one night in 2017 (Crisis, 2018) while 274,100 people sought local authority assistance with 59,100 households accepted as homeless in 2016/17 (Crisis, 2018). Official figures are likely to be a significant underestimate of the overall levels of homelessness (Crisis, 2018; Watson et al, 2016) such is the hidden nature of many people's experiences of homelessness; one Canadian study suggests that there are 3.5 'hidden homeless' for each one appearing in the statistics (Eberle et al, 2009). 
Much of the existing literature examining the role of and experiences within hostels stems from public health initiatives. There is a focus upon drug and alcohol use and recovery (Neale and Stevenson, 2015; Neale and Brown, 2016), mental health and suicide (Nordentoft and Wandall-Holm, 2003; Votta and Manion, 2004) and, increasingly, the challenges of youth (Hall, 2006), ageing, and palliative and end of life care (Holt et al., 2012; Ko and Nelson-Becker, 2014; Sumalinog et al. 2016; Tobey et al. 2017). Baldry et al. (2006) found in a study of homelessness among former prisoners in Australia that addressing issues such as drug use, lack of employment or structural support was unlikely to succeed without prioritising housing and accommodation and in line with this there has been growing interest in Housing First programmes. Despite this, however, deficit model thinking and 'staircase to transition' models of homeless support which see people progress up the housing ladder rung by rung (Sahlin, 2005) remain prevalent.

Sahlin (2004) and Busch-Geertsema and Sahlin (2007: 75) have touched on hostels' ability to protect/control, punish and deter, and act as a 'worse alternative' for some. Meanwhile, within the criminological sphere, the focus has been on approved premises and probation hostels (see for example Barton, 2004; Cooper, 2014; Cooper and Sim 2013). Parsell and Marston (2016) argued that supported housing providers use 'weak paternalism' to support individuals' autonomy development. They note that much of the work undertaken is aimed, implicitly or otherwise, at enabling people to compete in a marketized society with disadvantaged life opportunities used to justify intervention. Parsell and Clarke (2017) argue that we should eschew the idea that advanced liberalism is a coherent social project permeating all domains of society/governance and instead understand advanced liberalism as "a broad family of ways of thinking about and seeking to enact government" (Rose et al. 2006: 98 cited in Parsell and Clarke, 2017:8) with hostels often mobilizing some of those ways of thinking and acting. Furthermore, Rachel Dobson (2015) suggests that we should avoid deterministic approaches which suggest that practitioner and service user responses are conditioned and constrained through social policy and other external influences. She maintains that we need to develop a relational conceptualization of homelessness and homeless support services and practitioners and that doing so allows us "to substantiate the processes through which the local state comes into being via day-to-day practices and interventions with the users of services." (Dobson, 2015: 703).

Sarah Johnsen and colleagues (2018) have sought to better understanding the role of a range of 'hard' and 'soft' techniques of social control covering force, coercion, bargaining, influence and tolerance which are utilized when working with street homeless individuals. Their typology of homelessness and social control "seeks to conceptualize the full gamut of responses to street homelessness, distinguishing between five 'modes of power' that may be used in attempts to alter homeless individuals' behaviour." (Johnsen et al, 2018: 2). Elsewhere, Beth Watts et al. (2017) have developed Ruth Grant's (2006) three primary criteria for judging the legitimacy of the deployment of power (whether it serves a legitimate purpose; whether it allows for a voluntary response; and by its effects on the character of the parties 
involved), to include a fourth element: whether it is an effective, proportionate and balanced means to pursue the (legitimate) purpose(s) for which it is deployed, applying this framework to the control of homelessness. Such a framework, particularly when combined with Johnsen and colleagues' typology of social control, provides a valuable evaluative tool for considering the role and efficacy of the techniques deployed by hostels and organizations working with homeless populations, and this article argues that Johnsen and colleagues' (2018) typology of social control can be extended to cover the experiences of homeless people beyond those on the street.

\section{Methodology}

This article draws upon a subset of qualitative interviews conducted with a group of men between 2010 and 2012 as part of a doctoral research project examining experiences of unemployment and its impacts upon crime and senses of identity among men in Stoke-on-Trent (see Mahoney, 2015; Mahoney and Kearon, 2017). Several participants resided in homeless hostels, with two sites providing access. Four lived in Hostel 1 and nine (including one who had moved across from Hostel 1) in Hostel 2. One further participant had recently moved from Hostel 2 to supported accommodation. Interviews ranged in length from thirty minutes to three hours with everyone being interviewed twice. Findings were supplemented by observations of communal areas while waiting for participants and interview rooms to become available. Hostel 1, which is run by a local charity as part of their broader aims of addressing the challenges posed by homelessness and mental health, offered accommodation for anyone aged 16 to 69 while Hostel 2, which is part of a global organization, focused on supporting young people up to the age of 25, although it was not uncommon for people living there to be well into their late twenties. Both sites stated that the accommodation was safe and secure and offered direct access accommodation, subject to availability, to men and women for up to two years.

\section{Homeless Hostels, discipline, legitimacy and regulation}

Garrett (2007: 203)argues that it is important to 'look backwards' when examining key policy changes, decisions and their impacts on certain elements in society so that we might "prompt a 'rupture' from dominant, taken for granted ways of understanding". It is then worth briefly considering the history of sites of discipline, and that of hostels, before examining the disciplinary and regulatory mechanisms which are infused within their practices.

Sites of discipline are diffuse and heterogenous, ranging from the benign, (e.g. the education system and workplace - particularly in industrial factories and workshops), through militarized discipline in the armed forces, to the disciplinary regimes in wider society - historically characterized by former work and poor houses, mental health institutes and the prison system (see Foucault, 1991: 141-149). Foucault documents a number of characteristics including the timetabling and regulation of the day, strict codes 
of conduct, and the adoption of techniques aimed at maintaining order and discipline encouraging the inculcation of this into the routines and actions of the individual.

Hostels deploy a variety of mechanisms to achieve their aims and benign forms of support on offer from more 'hands off' organizations (see Parsell and Clarke, 2017), are inseparable, in practice, from the containments, coercion and surveillance to which this marginal and precariously placed group are subjected. These two hostels have very different histories. One belongs to an international organization founded in the $19^{\text {th }}$ century which initially sought to provide support to working men throughout London before expanding, developing an increasing focus upon homelessness and unemployment in the $20^{\text {th }}$ century. The second belongs to a former local housing group which expanded to provide support for people dealing with challenges posed by mental health conditions, substance dependence, homelessness and sex work; many of which are, as documented elsewhere, closely related. The operation of both hostels is influenced by wider societal, economic and political trends. The 'Places of Change programme' instituted by the New Labour Government pushed hostels to engage in empowerment and providing activities targeted at activity, employment, education and or training, "that support people to make positive changes in their lives and move on to independent or more appropriate supported accommodation" (Gov.uk n.d.). More recently, they have been heavily impacted by ongoing austerity in the U.K. which has had a profound impact upon funding streams and has seen them becoming increasingly creative as they seek to continue providing opportunities for service users, however this is not without problems.

Baldry et al (2006) and Dwyer et al (2014) show that stable accommodation is crucial in tackling other problems. Cooper (2014: 25) found that, despite acting as semi-penal institutions, hostel accommodation was beneficial, particularly for some women where they were involved in group work, and "cultivated an 'institutional intimacy' and collective empowerment", with some stating improvements in a sense of safety and stability. These benefits, stability and positive bonds that they can help to foster are reflected in the narratives of the men who took part in this study.

Hostel 1 provided assistance and rehabilitation where required:

"They ascertain how you feel about yourself and get a rough idea about where you are and the rest of it and then they'll work with you on that ...you will agree a plan of action with you so they'll say 'well what about this one?'. You'll have ... a lot of input into this. They don't get you to do anything you don't want to do, but ... if you decide you want to do that, they'll support you in carrying that through, so even if it's reminding you or they'll make the phone call for you. Erm, they've got counselling ... They'll get you in contact with drug and drink places. Err, housing, benefits, they'll help you with so all of that hands-on practical stuff they're very good at...things like err keeping the place tidy, cooking for yourself and help with that. Err, getting your washing done and pretty much everything they'll give you a hand with, all with an eye to 
get you independent living and err and drug free if that's what you want to be. If you don't want to be then how you can manage yourself best with your drug problem, so yeah, they're great like that, really good...assisting with problems and then feeding back responsibility in due course...I know there is...one guy in particular, and he's been here quite a long time, maybe eighteen months or so, and he's a drinker. He doesn't want to stop and he doesn't do anything. I mean if ...they didn't get his appointments and drive him to them he wouldn't go, so they don't feed it back to him so much. Maybe they'll want to in the future but they don't push it on him so if he's not capable or he doesn't want to then they'll just make sure that he gets, gets there and err, that he gets the sort of help needs, or that he says he wants."

\section{I: "You think it's the right sort of model?"}

"I think it's a great sort of model yeah ...I mean I'm very good at picking fault in things and I can't really pick anything with this place...these are real staff...they have nothing to do with the structure of the hostel or anything, this is just how they're doing their jobs...I'll go to [his keyworker] and say 'I've got a problem with this' and they'll deal with it. But the actual structure of the place, how they do it. Err, it's all kept perfectly clean and tidy and it's great, it really is a very good place.” (Brian, 41: Hostel 1)

Echoing Parsell and Clarke (2017) the supportive ethos of that institution was important to Brian and the multiplicity of approaches meant that he gradually redeveloped his autonomy. He spoke to the idea that the hostel "avoids 'pressuring' homeless people to alter their behaviour, [and] focuses on supporting them to change if and when they self-identify as being ready to do so." (Johnsen et al. 2018: 14) adopting a tolerant approach to those who either do not want to, or are not in a position to, change their circumstances. Parsell and Marston (2016) claim such approaches assist homeless individuals and service users in making sense of their circumstances and the challenges which they face. Through agreeing an action plan, the individual expresses a desire to engage and progress, with an increasing sense of ownership and associated autonomy while living there. However, as Parsell and Marston (2016: 11) note "Supportive housing's focus on changing individuals is consistent with a neoliberal paternalist analysis of welfare." Thus, in agreeing personalized action plans, the complex challenges facing those requiring welfare support remain cast at an individual rather than societal level.

Brian suggests a recognition of residents' needs, many of whom have experienced persistent drug and alcohol dependency and prolonged homelessness, are met, with some struggling to achieve this independently. This support is not unconditional, however, and compliance with the hostel's aims and structures is essential; actions are subtly infused with frameworks aimed at regulating service user's behaviours. Watts et al's (2017) development of Grant's (2006) criteria on the legitimacy of the deployment of power can assist in understanding effectiveness and legitimacy here. In Brian's case, the aim is to assist the individual in achieving agreed goals (a legitimate purpose), which he has been 
involved in the formation of from an early stage (a voluntary response) with the aim of tackling drug dependency and a lack of autonomy (the effect on the character involved). Moreover, they gradually returned independence to Brian, facilitating his autonomy, thus suggesting that Watts et al.'s fourth test - that the approach is an effective, proportionate and balanced means to pursue the (legitimate) purpose(s) has also been passed.

Brian's positive outlook was aided by the fact that he had, in line with the 'staircase to transition' model, been one of the lucky few to have moved from a room to a bedsit on the top floor, later progressing into supported housing. While still within the same institution, the bedsit afforded him freedom and autonomy regarding his eating arrangements (bedsits had their own cooking and food storage facilities) and day-to-day movements within the hostel. His experiences mirror those discussed in Parsell and Clarke's (2017) work in Australia, with increased autonomy developed as people progress through the hostel into more independent living arrangements within the same location, and fewer paternalistic responses in independent living quarters.

However, Brian's increased freedom, arguably came at the expense of some others, with access to the bedsits on the top floor controlled by keycard access, something discussed by Craig, who had also 'moved up':

I have to use me keycard, you know? To get out on the landing, you've seen me use it haven't you? I've just gone to use it on this one (Craig, 42, Hostel 1).

Hostels, already secure sites, partition, organize and supervise space, control internal access and limiting the movements and activities of residents. Parsell and Clarke (2017) noted the dissatisfaction of service users who had reached 'Level Six' (independent living quarters within the hostel). They suggest that such approaches are undertaken to protect those who have 'moved up' from the risks of associating with people who have not attained the same level of independence and may be seen as less responsible but sits in tension with the aim of returning autonomy and responsibility to the individual.

Echoing Brian's positive experiences, some felt that they had been able to develop both develop personally and socially:

"moving 'ere [here], it was just great because I had all me mates, I started getting close to people and that, and started getting really good friends and that, 'cause there are some really, really good people in there." (Hatman, 26, Hostel 2)

"It's kind of really brought me out of my shell a lot since I've been here. I'm a lot happier I'm a lot more jokey than I used to be, I used to be really reserved... having friends for the first time in like six years and my relationship. It's nice to have friends." (Tim, 23, Hostel 2) 
They suggest that a period of stability facilitated new bonds and friendships and saw improvements in self-esteem and relations with people around them (Zuffiano et al.2016). Mirroring Hall's (2006) study, hostels also provide an escape from a home environment which some felt they needed to leave care of poor relations with family and ongoing health issues. Stan, when asked why he went to Hostel 2, stated that:

"II was] constantly falling out with my mum's boyfriend, but erm the main reason is that I have insomnia and err at the time it kinda hit me in the face why I have insomnia. At first I thought it was me mum and her boyfriend constantly arguing so I thought 'let's get out of the house for a bit, the [hostel] will take me in if I tell 'em the situation... which they did." (Stan, 21, Hostel 2)

Stan supports Parsell and Parsell's (2012) critique of homelessness as a choice, with his decision influenced by external circumstances and constraints. This was reflected in the experiences of 27 -year old Gandy who had spent time in both hostels who also had strained relations with his family; something not helped by the fact that he had previously stolen from them to support a heroin addiction. It was only after moving to a hostel and 'coming out' as homosexual, that relations began to improve. Complex internal personal conflicts can prove to be highly debilitating and the space and support through a hostel can help overcome some of the challenge posed.

Hostels may, furthermore, provide new opportunities, assisting in developing new forms of capital. Gandy, because of his experience working in IT before developing a heroin addiction and becoming homeless, was assisting the hostel and an LGBT+ charity in developing their IT infrastructure; such opportunities proved beneficial for both the hostel and individual. In Hostel 1 people were encouraged to engage with support groups, initially as service users and then as mentors while developing skills and qualifications in (for example) food hygiene and catering. In Hostel 2 there was a heavy focus on community roles, basic skills development, CV writing and opportunities to work as Youth Activities Coordinators. We see the move to engage people in activities related to employment, training and engagement with mainstream society and the workforce, again suggesting that the hostels are acting with legitimate purpose, engaging residents in a voluntary manner aimed at benefiting them and their character, in a fair and proportionate manner (see Watts et al. 2017). This proved vital for Shaun (38, Hostel 1). He and his girlfriend, who lived in the same hostel, aspired to run own catering business off the back of his catering experiences at the hostel in spite of ongoing heroin addictions; however, this aspiration was limited to running a burger van. On the one hand, Shaun developed positive relations, a sense of purpose, belonging and wellbeing, and the development of new aspirations. On the other, the efficacy of such opportunities becomes questionable, particular when considering the impact of lowskilled work upon future social mobility and his ability to 'get on'. While Shaun's aspirations are not in themselves problematic, the diversity of the catering trade indicates that these aims are likely to have 
been tempered considerably, shaped by ongoing long-term declines in employment options available to low-skilled individuals (see inter alia Allen, 2012; Kuhn, 1998) which sees a growing, precarious proportion of society compressed into an ever-shrinking world of effective and meaningful employment opportunities. There are then hidden constraints placed upon aspirations and a tempering of expectations, compounded by histories of drug dependence.

Residents stated that these two hostels provide greater support than other direct access institutions through their focus upon training and recovery. However, these opportunities were frequently influenced by the hostels' own requirements. Activities fill part of the day with 'constructive' routines and activities, encouraging them to inculcate certain behaviours and norms (Foucault, 1991) while simultaneously, because of the nature of the roles and activities available, fostering the acceptance of low-skilled roles in society with limited chances of advancement. This reduced overheads for the respective organizations by enabling them to draw upon a ready supply of voluntary labour; this is hardly surprising, particularly in the current climate of austerity. The decline in available bed spaces across England and Wales; changes to Universal Credit; and government funding cuts for homelessness has meant that hostels and service providers have had to develop alternatives means to survive engaging residents in voluntary work within the institution is one tool at their disposal. For those in Hostel two for instance, to potentially secure employment as a youth activities coordinator, six months to two year's voluntary experience was required. With a maximum residency period of two years, however, and a significant number of residents being shepherded towards the programmes, many of them would struggle to achieve a more permanent, stable position in the future.

Developing skills useful to organizations coincides with the increasingly important role played by charities and the third sector as the neoliberal state continues to abdicate responsibility. As discussed by Garland (2002), and revisited by Cooper (2013), the third sector fulfills an increasingly prominent role in controlling elements of the population deemed problematic and in need of managing; homelessness forms one element in this. However, echoing the experiences of working-class communities in Teeside (see for example MacDonald et al 2005; Shildrick et al 2014), this can leave vulnerable and marginalized groups at best able to 'get by', without creating opportunities to develop the capital that will enable them to 'get on' as opportunities are increasingly geared towards the needs of the institution rather than the individual. This is symptomatic of approaches towards the homeless which sees them as a problem group to be disciplined, with a lack of meaningful support for them in overcoming complex structural and personal challenges. Even where providers advocate for engagement in programmes aimed at developing food hygiene, activity coordination and other skills, "encouraging participation was framed as a means towards teaching them to develop independence in market terms" (Parsell and Marston 2016: 212) reducing them to their economic rather than social potential. 
Some of the other activities promoted, including on induction programmes (notably in Hostel 2 where day trips were arranged), provided leisure activities to facilitate a higher quality of life, socialization and inclusion among residents (Trussell and Mair, 2010). The appropriateness of such activities was questioned, however, indicating that they weren't always perceived as conducive to the individual getting on in life:

I've just had a phone call then off of [keyworker] saying are you going to find out about this SIA licence, because I wanna go into security. I wanna go abroad as well but they don't wanna help me with my passport and things like that. They're taking us out like gokarting and things like that, snowboarding. (Scott, 24, Hostel 2)

Scott's views were compounded by a perceived failure to deliver. Given that support is often needed at a pivotal point in someone's life, delays can significantly impact upon the chances of someone being able to get on:

No, no one's come back to me like. That's why I don't like this place...you have your induction when you're here for your first month: 'Yeah, we'll help yer. We'll do this for yer, we'll do that for yer.' And it's like 'well great! I'll stay here then!' But when your induction's finished, you don't hear shit off them...I just want to change me life around now but I'm not getting the help I want. If I don't get it after Christmas then I might have to resort back to crime. (Spanish, 25, Hostel 2)

Spanish was keen to develop his autonomy, turning his back on crime in the process, but was aware that he lacked the requisite tools to achieve this. His narrative contrasts with Brian's earlier commentary on the benefits of such approaches, and through failing to provide the requisite resources for supporting Spanish in developing his autonomy, challenges the legitimacy of the hostel's operations (Watts et al. 2017). His response contrasts with Hall's (2006:149) argument that plans made between residents and key-workers would "come to nothing or be overtaken by events" because of failings on the part of the young person. While Hall notes that there are structural challenges facing the young people in his study, his argument is uncritical of the role of keyworkers; Spanish indicates that relations, roles and signs of progress are far more complex than are often perceived. Without effective and timely interventions, some will fall through the net and find themselves back in the same precarious, and at times criminogenic, positions faced prior to moving there.

This is not to exonerate the actions of residents with some interventions implemented because of their actions. There was an emphasis on self-development where they had capacity to do so through engaging in activities including CV building and development workshops, while abiding by the rules of the hostel. These rules, however, were often broken, resulting in enhanced surveillance, closing of certain spaces (e.g. IT facilities where equipment went missing; a regular occurrence in Hostel 2) and a resulting loss of privacy. Limitations placed on access represent coercive forms of social control intended to 
encourage compliance through the threat of deprivation of goods, access or services (Johnsen et al. 2018).

Movements and routines were further influenced by strict access requirements preventing guests from entry to either institution after 10pm, and never to residents' rooms. Hostel 1 had staff-controlled access to the building via a permanently locked door, while Hostel 2 had a 24-hour manned reception desk requiring non-residents to sign in; staff then are able to exercise considerable influence over the actions of residents and their use of space (Hansen Löfstrand, 2015). One of the most significant functions of these manned and controlled access arrangements is that they can adopt more forceful methods of controlling access and refuse entry to residents deemed too intoxicated (whether through excessive drug or alcohol consumption) until they have sobered up. While this can be construed as steering people to take increasing responsibility for their own welfare, it ultimately leaves vulnerable people excluded from their own place of residence - itself a site of exclusion from the wider societal body.

Over and above the control of space, the day was also routinized and timetabled. There were set meal times in both hostels, and in the case of one of the locations considerable competition for food. If people didn't get to the canteen in time, they risked finding themselves stuck with the less desirable option:

"If you're not there for your tea four til six, they've got two items on. If you don't like one of them, you've got to be there early because that one will run out, the one that you like. So you've gotta be there." (Storm, 23, Hostel 2)

"there's hardly any carbs in it, in the food in here. And then you 'ave to rush to get your food early, at four, because if you don't get there early all the good stuff's gone and you're having just crap...you're allowed five items." (Scott, 24, Hostel 2)

This led to prioritization of food and getting in early to ensure that they got what they wanted, again conditioning responses to achieve the most advantageous result. Alternatively, some might miss out altogether, enflaming tensions:

'I do get angry. It's like they wouldn't serve me breakfast on me fuckin' birthday.' I was two minutes late, right, cos I was enjoying me shower cos I treated meself to some proper shower gel cos I'm skint all the time, so I was having a proper shower. Woo! It's me birthday! Twenty-five and I'm stuck in a fuckin' hostel! Trying to make the most of it. I couldn't even have a coffee or anything. I was two minutes late for me breakfast and they wouldn't give me a bowl of fuckin' cornflakes. When I pay me rent! So I went mad. I threw a few chairs about and said 'you lot are fuckin' mental! I pay my rent! It's my fuckin' birthday as well!'. I went upstairs and smashed my cupboards in. Staff come up 'Oh, why are you shouting? All the other residents are scared'. So I just said 'look man, bring me a bowl of bran flakes because I'm fuckin' angry. I pay me rent and I should get 
what I pay for. You know what I mean?' and they served, the cheek of it! They served someone else after me! That's why I kicked off as well. Fuckin' bastards!” (Spanish, 25, Hostel 2)

As identified by Foucault (1991:149) rhythms are established and cycles of repetition regulated through stringent enforcement of timetabled events, meals and activities in moves aimed at instilling routines intended to discipline people into developing the skills required for the workplace (despite all participants having previous experience of work). Techniques are diffuse and inculcated into daily practice through a process of 'normalization' (1991: 184) aimed at fostering engagement with the wider societal body. However, it should be remembered that while inculcating these behaviours, individuals are still in a position to exercise their agency, albeit within the constraints imposed by the institution. Spanish was aware of the timetable and, having prioritized a shower over breakfast, can be seen to have exercised his right to choose to enjoy his shower rather than heading down to breakfast in the allocated timeframe albeit constrained by the undesirable circumstances which he faced.

The loss of privacy however was perhaps one of the most significant and coercive tools in operation which stemmed from both fellow residents and staff. Some chalked this up as fun:

it sounds really weird being at like a Youth Campus and everything, but it's quite chaotic here. Like the stuff that goes on, it's like amazing, so I just sit back and watch it really. Sometimes I create it myself. (Stan, 21, Hostel 2)

Later saying:

We get along. Like playful banter, mock each other really, that's all it is now. I don't dislike anyone but, well, I'm not the nicest to people. It's like I say harsh things to people. I do, but they just need to learn it's only a joke... (Stan, 21, Hostel 2)

Reflective of Holt and colleagues' (2012) analysis of the experiences of older men, however, for those on the receiving end, such actions had potentially detrimental effects upon relations with family and significant others:

"I've been getting agitated by people in here who have nothing better to do than wind people up, so mine and my girlfriend's relationship isn't at its best. She decides to ring me at the worst times and when I don't answer she gets worried." (Storm, 23, Hostel 2)

Storm's sentiments resonated with Tim (26, Hostel 2), with the close confines and the lack of privacy being a particularly negative side of his experiences. Tim was concerned about falling into "a rut" after a relationship with another resident broke down "because there were too many people poking their noses in and it got too much for us". Hostel residence then can come at significant personal cost. Stan, Storm and Tim emphasize the challenges posed for and by working with young people in particular, 
alongside the impact of boredom and a lack of engagement, underscoring the difficult role of service providers in supplying safe, secure accommodation for people from diverse background facing a multitude of challenges.

There were further intrusions from staff with residents in Hostel 1 expected to vacate their rooms daily to allow housekeeping access to clean, while in Hostel 2, regular staff access was also part of life; something that Storm took umbrage with:

'I've had a bit of a falling out today, well last night, with maintenance. They'd been in my room, erm, not told me they're going in my room. I know I've not got a tenancy agreement but I'm still a customer [and] they should let me know that they're going into my room ...erm, they said that my extension lead didn't pass the PAT test [Portable Appliance Testing conducted to ensure that appliances are safe to use]...they've taken it out of my room, left me a note, said they'd bring me one back for last night...At the end of the day it's my property. If you tell me not to use it, I won't use it, but you don't take my property out of my room without my say so or without letting me know that you're doing stuff. (Storm, 23, Hostel 2)

Storm drew attention to the precarious position in which he found himself and the conflict between his perceived right to privacy (despite no tenancy agreement), his construction of himself as a 'customer' in a consumer driven society, and the day-to-day operation of the hostel. He spoke to the lack of privacy and ownership of space which many young and precariously placed people experience, and the levels of surveillance which they may encounter as staff - themselves often relative strangers- are expected to be allowed into the individual's 'private' space. He later drew attention to the differential treatment between the hostel accommodation and nearby flats operated by the same organization, mistakenly attributing their ownership and day-to-day running to the council:

Well you've got an agreement but whereas in the flats if staff knock on your door you don't have to let them in, but in here you've got to let them in 'cos it's like that whereas they've got a tenancy agreement with the council. (Storm, 23, Hostel 2)

He highlighted the contrast between those with their 'own space', and those living in shared accommodation, indicating possible tensions arising due to his position on the 'staircase of transition'. There are then different levels of service and expectation from both residents and hostels depending on the style of accommodation that the individual is living in, however these different types of accommodation also play a significant incentivizing role.

Both hostels provided incentives to advance one's housing career via a variation of the Swedish 'staircase of transition' model in spite of evidence of the failings of the model to achieve its aim of decreasing homelessness (Sahlin, 2005). Incentives and disincentives represent a powerful tool for 
service providers to engage residents and service users through another tool of social control 'bargaining' - which is less forceful than more coercive approaches (Johnsen et al. 2018). The offer of 'moving up' in Hostel 1, or gaining a larger degree of autonomy through securing a flat in Hostel 2, can be a powerful motivator to conform:

\section{"Me and me brother have been trying to get a flat for a while but we're both in arrears here at the moment so accounts won't put us on the list until the arrears are paid." (Stan, 21, Hostel 2)}

This is especially the case given the additional freedom and independence which comes with it: I go food shopping because I'm in a bedsit here. I don't get my meals cooked for me here, you know? I mean some of them do, you've got people on full-baord, half-board and then people in bedsits. I'm in the bedsits I am, whereas you know, my charges are a minimum because like I have to buy everything, you know? Get me own. (Craig, 42, Hostel 1)

Choice, autonomy and a semblance of self-control are powerful motivators for change and engagement (Harper, 2007). Grant (2006: 29) notes that "An incentive is an offer of something of value...meant to influence the payoff structure of a utility calculation so as to alter a person's course of action. The person [or organization] offering the incentive means to make one choice more attractive to the person responding to the incentive than any other alternative." On purely economic grounds, such an approach is rarely unethical, however when considering the moral and political implications, the approach becomes more problematic due to the manner in which power is exercised over another.

Echoing Sahlin (2005: 125), the promises of 'moving up' frequently went unfulfilled in a timeframe deemed acceptable by the people to whom such progress was promised:

"You know they said they'd move me over there in four weeks and it's been five weeks now, and they said they'd move me into one of them flats over there." (Spanish, 25, Hostel 2)

"This place is a joke. It is, it's a joke. 'specially when they're moving people across there that haven't got kids and they've got, either they're on the sick and they're getting loadsa money and I'm stuck in this building with seventy pound a fortnight struggling when I could be across there." (Scott, 24, Hostel 2)

The 'bargain' is presented as helping people move on when staff deem them ready and able to support themselves, so long as all other expectations are met. Opportunities to move on through the system are alternative methods for controlling and encouraging engagement, however through raising the expectations and aspirations of the individual and then being perceived as having failed them, the ethicality and legitimacy of these incentives is called into question. While such an approach may pass 
Grant's (2006) key tests of the deployment of power, they arguably do not meet Watts et al's (2017) fourth test because, despite being a legitimate means to pursue the purpose for which it is deployed failing to meet the expectations that have been built up, the approach becomes ineffective and unbalanced.

\section{Conclusions}

This article argues that even the most benign forms of support are inseparable from coercive, regulatory, routinizing and surveillance strategies to which homeless populations are subjected. While residents demonstrated agentic responses and developing autonomy, expressions were conditioned and constrained through the frameworks to which they are subjected. Policies and practices mean that hostels and their staff must negotiate a balance between accommodating a range of people who often face significant health, education, employment and addiction related hurdles in a safe environment, and preparing them for life after they have left the institution. Both hostels focused on supporting individual choice and autonomous development, thereby respecting them as agentic individuals, however the undercurrent of paternalism and deficit model thinking leaves this marginalized and stigmatized group subject to a range of control mechanisms.

There is little direct compulsion to engage in programmes of reform, however, 'soft' and 'hard' techniques of social control ranging from tolerance, through coercion, bargaining and influence, to force (Grant, 2006; Johnsen et al. 2018), are embedded within practices and the typology of social control developed by Johnsen and colleagues provide a useful tool enabling us to explore their nature and application within the hostel setting. The pervasive use of surveillance, routine and a focus on individually agreed development plans slowly embed discipline and regulation in the often-chaotic lives of their residents.

As in Brian's experience, there is an increasing body of evidence to suggest that where done well some interventions can be beneficial in encouraging residents to meet goals and engage with programmes and this can provide significant benefits for the individual in question. However, in many cases people face sanctions and onerous conditionality over and above that experienced within wider society. Certain behavioural traits, skills and attitudes are encouraged to mitigate for the vulnerability and exclusion these people face, but still within the confines of largely unfulfilling and precarious roles within society. Reinforcing the construction of homelessness as an individual failing and deficit of character, as the practices explored here do, means that attention is diverted from the endemic structural disadvantages latent within society and continues to compound the marginalization of a precariously placed and vulnerable part of the population.

Hostels then should ensure that the interventions they utilise work towards a fair and legitimate goal. Realistic, achievable expectations should be set agreed by hostels and residents. Staff should, 
furthermore, be supported in developing their own networks and awareness of the diversity of opportunities potentially available should the individual wish to pursue a particular path, developing residents' existing skillsets where possible. It is not problematic per se for activities to be mutually beneficial for the organization and service user provided that said activities assist residents in achieving their goals of autonomy and independence in an open and honest manner and do not prioritize the needs of the institution. Hostels over-promising and under-delivering poses significant challenges to their ability to operate fairly and legitimately and risks alienating service users at a time when they may need support the most. Thus, while many of the activities may exhibit the legitimate deployment of power, where expectations are not met or hopes are built up with little chance of fulfillment, this can be called into question.

\section{Acknowledgements}

I would like to thank Ingrid Sahlin and the anonymous reviewers for their helpful comments on previous versions of this article.

\section{Bibliography}

Allen M (2012) Quality Standards in Homeless Services, Housing Led Approaches and the Legacy of 'Less Eligibility' European Journal of Homelessness 6(2) pp.159-166

Mahoney I and Kearon T (2017) Formulating the post-industrial self: the role of petty crime among unemployed, working-class men in Stoke-on-Trent in Walker, C. and Roberts, S. (eds.) Masculinity, Labour and Neoliberalism: Working-Class Men in International Perspective, London: Palgrave Mahoney I (2015) Graftin' up 'anley duck: Narrating the influence of unemployment upon identity and crime in Stoke-on-Trent [unpublished $\mathrm{PhD}$ thesis], Keele University

Baldry E, McDonnell D, Maplestone P and Peeters M (2006) Ex-Prisoners, Homelessness and the State in Australia, Australian \& New Zealand Journal of Criminology, 39(1) pp.20-33

Barton A (2004) Women and Community Punishment: The Probation Hostel as a Semi-Penal Institution for Female Offenders. The Howard Journal of Criminal Justice 43(2): 149-163

Busch-Geertsema V and Sahlin I (2007: 75) The Roles of Hostels and Temporary Accommodation, European Journal of Homelessness 1:1 pp.67-93

Cooper V (2013) No Fixed Abode: the implications for homeless people in the criminal justice system, London: Howard League for Penal Reform.

Cooper V and Sim J (2013) 'Punishing the Detritus and the Damned: Why Prison in Liverpool and the Northwest?' in D Scott (ed.) Why Prison? Cambridge: Cambridge University Press. 
Cooper V (2014) 'Gendered Geographies of Punishment' in V Canning (ed) Sites of Confinement, European Group for the Study of Deviance and Social Control.

Crisis (2018) The Homeless Monitor: England 2018 available at https://www.crisis.org.uk/media/238700/homelessness_monitor_england_2018.pdf $\quad$ (accessed 21st June 2018)

Dobson R (2015) 'Power, Agency, Relationality and Welfare Practice' Journal of Social Policy, 44(4) pp.687-705

Dwyer P, Bowpitt G, Sundin E and Weinstein M (2014) 'Rights, responsibilities and refusals: Homelessness policy and the exclusion of single homeless people with complex needs' Critical Social Policy, 35(1) pp.3-23

Edgar B \& Meert H (2005) Fourth Review of Statistics on Homelessness in Europe, European Observatory on Homelessness (Brussels : FEANTSA).

Eberle M, Krauss D, Serge L (2009). Results of the pilot study to estimate the size of the hidden homeless population in Metro Vancouver.

Foucault M (1991) Discipline and Punish: The Birth of the Prison, New York: Vintage Books

Garland D (2002) The Culture of Control, Oxford: Oxford University Press

Garrett PM (2007) 'Sinbin' solutions: The 'pioneer' projects for 'problem families' and the forgetfulness of social policy research. Critical Social Policy, 27(2) pp.203-230

Gov.uk (n.d.) Benefit Cap, available at https://www.gov.uk/benefit-cap/benefit-cap-amounts accessed 4th Sept 2018

Grant R (2006) 'Ethics and Incentives: A Political Approach' The American Political Science Review, 100(1) pp.29-39

Guentner S, Lukes S, Stanton R, Vollmer BA and Wilding J (2016) Bordering practices in the UK welfare system' Critical Social Policy 36(3) pp.391-411

Hall T (2006) 'Out of Work and House and Home: Contested Youth in an English Homeless Hostel' Ethnos, 71: 2, pp.143-163

Hansen Löfstrand C (2015) 'The Policing of a Homeless Shelter: Private Security Patrolling the Border of Eligibility' European Journal of Homelessness 9(2) pp.17-38

Harper E (2007) Making Good Choices: How Autonomy Support Influences the Behaviour Change and Motivation of Troubled and Troubling Youth, Reclaiming Children and Youth, 16(3) pp.23-28 
Holt N, Christian J and Larkin M (2012) 'Maintaining Connectedness: Exploring the Experiences of Older Homeless Men Living in Hostel Accommodation' Journal of Community and Applied Social Psychology, 22, pp.485-501

Johnsen S, Fitzpatrick S, \& Watts B (2018). Homelessness and social control: a typology. Housing Studies, 1-21

Ko E and Nelson-Becker H (2014) 'Does End-of-Life Decision Making Matter?: Perspectives of Older Homeless Adults' American Journal of Hospice and Palliative Medicine, 31(2) pp.183-188

Kuhn T (1998) 'The Declining Labor Market Outcomes of the Less Skilled: Can Fiscal Policy Make a Difference?' Canadian Public Policy/Analyse de Politiques, 24(3) pp.370-377

MacDonald R, Shildrick T, Webster C, \& Simpson D (2005). Growing up in poor neighbourhoods: The significant of class and place in the extended transitions of 'socially excluded' young adults. Sociology, $39(5), 873-891$.

Neale J and Brown C (2016) 'We are always in some form of contact': friendship among homeless drug and alcohol users living in hostels, Health and Social Care in the Community 24(5) pp.557-566

Neale J and Stevenson C (2015) 'Social and recovery capital amongst homeless hostel residents who use drugs and alcohol' International Journal of Drug Policy, 26(5) pp.475-483

Nordentoft M and Wandall-Holm N (2003) 10 year follow up study of mortality among users of hostels for homeless people in Copenhagen British Medical Journal 327 pp.81-83

Parsell M and Clarke G (2017) 'Agency in advanced liberal services: grounding sociological knowledge in homeless people's accounts' The British Journal of Sociology, pp.1-21

Parsell M and Marston G (2016) ‘Supportive Housing: Justifiable Paternalism?’ Housing Theory and Society, 33(2) pp.195-216

Parsell M and Parsell M (2012) 'Homelessness as a choice' Housing, Theory and Society, 29(4) pp.420434

Sahlin I (2005) 'The Staircase of Transition: Survival through failure' Innovation: The European Journal of Social Science Research, 18(2) pp.115-135

Sahlin I (2004) 'Enclosure or Inclusion? Urban Improvement and Homelessness Policies’ Open House International, 29(2) pp.24-31

Shildrick T, MacDonald R, \& Furlong A (2014). 'Benefit street' and the myth of workless communities. Sociological Research Online, 19(3). 
Sumalinog R, Harrington K, Dosani N and Hwang SW (2016) 'Advance care planning, palliative care, and end-of life care interventions for homeless people: A systematic review' Palliative Medicine, 31(2) pp.109-119

The Foundation Abbé Pierre and FEANTSA (2017) Second Overview of Housing Exclusion in Europe 2017, FEANTSA

Tobey M, Manasson J, Decarlo K, Ciraldo-Maryniuk, Gaeta JM and Wilson E (2017) 'Homeless Individuals Approaching the End of Life: Symptoms and Attitudes' Journal of Pain and Symptom Management, 53(4) pp.738-744

Trussell DE and Mair H (2010) ‘Seeking Judgment Free Spaces: Poverty, Leisure and Social Exclusion’ Journal of Leisure Research 42(4) pp.513-533

Votta E, Manion I (2004) 'Suicide, High Risk Behaviors, and Coping Style in Homeless Adolescent Males' Adjustment' Journal of Adolescent Health, 34, pp.237-243

Watson J, Crawley J and Kane D (2016) 'Social exclusion, health and hidden homelessness, Public Health, 139, pp.96-102

Watts B, Fitzpatrick S, \& Johnsen S (2017) 'Controlling homeless people? Power, interventionism and legitimacy'. Journal of Social Policy, 1-18.

Zuffiano A, Eisenberg N, Alessandri G, Kanacri BPL, Pastorelli C, Milloni M and Caprara GV (2016) 'The Relation of Pro-Sociality to Self-Esteem: The Mediational Role of Quality of Friendships' Journal of Personality, 84(1) pp.59-70 